\title{
CORRESPONDENCE
}

Correspondents are asked to be brief

Training of Surgeons

R. M. Kirk, F.R.C.s. . . . . . . . . . . . 468

College of Anaesthetists

D. W. Barron, F.F.A. R.C.S., and others .....468

Lymphocyte Reactivity in Pregnancy

J. S. Walker, PH.D., and others..........469

Cataracts after Renal Transplantation

G. H. Hall, F.R.C.P., and others. . . . . . . . 469

Contact Eczema in Agricultural Workers

T. A. J. Dawson, M.D., and

K. W. Scott, M.R.C.P.I.............. 469

Atheroma of the Aortic Bifurcation

R. S. Arnot, M.B., and J. H. Louw, F.R.C.s. . 470

Removal of Darning Needle with a

Fibreoptic Gastroscope

E. T. Swarbrick, M.R.C.P., and others. .....470

$\beta$-Thalassaemia, G-6-PD Deficiency and Atypical Cholinesterase in Cyprus

C. Kattamis, M.D., and others..........470

Herpes Simplex and Temporal Lobe Epilepsy

J. D. H. Millar, F.R.C.P., and others. ......471

Virus-specific Antibodies in Multiple Sclerosis

K. B. Fraser, M.D., and others .........471
E.N.T. Advances

L. Fisch, M.D...............471

Pancreatin as Source of Salmonella

R. M. Forrester, F.R.C.P., and

J. H. Keen, M.R.C.P................472

Anaesthesia by Acupuncture

Sir George R. McRobert, F.R.C.P........472

Effects of Dietary Fibre

Sir Charles Dodds, F.R.C.P., F.R.S., and others 472

Clofibrate and Fat Embolism

J. C. McPherson, M.D., and others.......473

Wetting and Soiling

G. C. Young, M.D., and

R. T. T. Morgan, B.A.............473

Puzzling Cases of Secondary Syphilis

I. Rose, M.R.c.G.P...........................473

Particles in Spleens

A. E. Stuart, F.R.C.P.ED..............474

Community Mental Health

U.P. Seidel, D.P.M. . . . . . . . . . . . . 474

Cold Drink and Syncope

Flight Lieutenant D. J. Rainford, M.B.....475

St. Stephen's Hospital Group

R. Lefever, M.R.C.G.P...............475

Payment by Colour

M. S. King, F.R.c.s...............475
Facial Palsy in Tetanus

M. Mishra, M.R.C.P.(U.K.), and

B. N. Sinha, M.D..........................475

Cryo-immunotherapy

R. J. Ablin, PH.D................476

Screening for Inherited Metabolic Disease

G. M. Komrower, F.R.C.P., and

I. B. Sardharwalla, M.R.C.P., ED.........476

General Practice Records

D. C. Wilkins, M.B..............476

Streptococcal Sore Throat

P. W. Ross, M.D................476

General Practitioner Grade

Catherine Woodyard, M.B............477

Joint Liaison Committees

W. M. Douglas, D.P.H...............477

Defence Society Subscriptions

J. D. J. Parker, M.B...............477

Local Authority Health Services

P. M. Green, D.P.H. . . . . . . . . . 477

William Capper Memorial Fund

M. G. Wilson, F.R.C.S.....................477

\section{Training of Surgeons}

SIR,-Mr. J. J. Shipman (29 July, p. 294) argues the case for reversing the present method of training surgeons. He considers that training should start in teaching hospitals, to be followed by examination for the diploma of F.R.C.S., and then be completed in peripheral hospitals. He additionally suggests that the title of senior registrar is dropped.

Surgical training requires apprenticeship to a master who gives personal instruction in the clinical and technical skills, who provides an example of the correct approach, and who individually metes out responsibility on the basis of close personal knowledge instead of from the trainee's place in a fixed programme. Judging from the high standard of young surgeons, this is not an idealized picture of what is already happening in the peripheral hospitals. There is no guarantee that such individual training would be given in hospitals devoted primarily to the instruction of undergraduates. Most of us learn best when under pressure from clinical necessity or impending examination. If the examination for F.R.C.S. is a test of practical surgery (and I believe it is) then it should come, as it does, at the end of this period of training.

I should also question Mr. Shipman's desire to drop the title of senior registrar. At some time in his career the aspiring surgeon must stand in open competition with his fellows for selection on the grounds of clinical and technical competence, suitable personality, and progressiveness. If he fails he must choose a less competitive field or a less competitive environment. If he succeeds he has earned the right to be given increased responsibility, to teach others, to display his progressiveness by embarking on research, and to follow special interests, knowing that his future is virtually assured.
It seems appropriate to mark this transition by a change of title.

The shortcomings in British surgical training ${ }^{1}$ do not lie in the period of practical instruction. The initial training of clinically competent surgeons should not be taken out of the hands of those who have proved their capability to teach. The peripheral hospital is in reality the postgraduate surgical teaching hospital.-I am, etc.,

London W.1

R. M. KIRK

1 Kirk, R. M., Annals of the Royal College of

\section{College of Anaesthetists}

SIR,-A referendum giving a careful and unbiased summary of the present position of the various organizations concerned with anaesthesia has been sent to every anaesthetist in Great Britain and Ireland. It seeks our opinion about the possibility of creating an independent college of anaesthetists.

We believe strongly that the creation of a separate college is the proper development for our specialty. We therefore hope that the view expressed below will be carefully considered by anaesthetists before they answer the referendum. We would emphasize that we are not advocating precipitate action but inviting support for this concept so that concrete discussions can begin.

The distinctive feature of a college of anaesthetists is that it would be the single autonomous body concerned with all aspects of anaesthesia and anaesthetic practice. Such a college would encompass all the functions both of the Faculty of Anaesthetists and of the Association of Anaesthetists, so ensuring that all important matters concerning anaesthesia would receive consideration and appropriate action by a single body, repre- sentative of all anaesthetists. This would facilitate communication between anaethetists and Government, the other colleges, and other relevant organizations.

Although financial consideration should not be the central issue in taking such a momentous decision, nevertheless, the cost cannot be entirely ignored. If the majority of anaesthetists want a college then financial problems should not deter them. The details accompanying the referendum show that the present level of payment by anaesthetists (and examinees) would be sufficient to support a dynamic college. Neither will capital expenditure present a problem. Some monies are already available in existing funds, and many anaesthetists would be proud to give initial financial support. The many commercial organizations associated with the specialty would also wish to help. Furthermore, an organization devoted to the relief of pain and suffering would inevitably attract substantial benefactions from philanthropic sources.

Anaesthetists are the largest single group of specialists. However, their most important body-the Faculty of Anaesthetists-is a subsidiary part of an organization devoted to a different specialty. This is anomalous in the very country which was responsible for so much of the modern development of anaesthesia.

It might seem that the foundation of a college of anaesthetists would be part of a general undesirable process of fragmentation within medicine as a whole. However, we see it as part of the evolutionary development of specialist medicine in Great Britain, leading eventually to a situation in which a federation or academy composed of equal partners could be established. For us, a college of anaesthetists would unify the several parts of the present fragmented organization of anaesthesia.

Anaesthetists have achieved complete clinical independence in the eyes of their 